\title{
RED TAPE IN HIGHER EDUCATION INSTITUTIONS: UAV POLICY
}

\author{
P. K. Freeman ${ }^{1}$, R. S. Freeland ${ }^{2, *}$ \\ ${ }^{1}$ Dept. of Political Science, The University of Tennessee, Knoxville, Tenn., USA - pfreelan@utk.edu \\ ${ }^{2}$ Dept. of Biosystems Engineering and Soil Science, The University of Tennessee, Knoxville, Tenn., USA - rfreelan@utk.edu
}

KEY WORDS: Drones, FAA, Precautionary Principle, Risk, UAS

\begin{abstract}
:
Reports over the past two decades have documented concern that the growth of regulation on research is reducing scientific productivity. While much of the burden comes from mandated standards, institutions increase the burdens when they add elective rules. This study examines regulatory responses in higher education to the implementation of domestic unmanned aerial vehicles (UAVs) in the United States of America (U.S.). The variance in UAV policies provides insight into regulatory responses to a controversial emerging technology. All higher education institutions share a common mission of education, research, and service, although the amount of attention given to each varies. UAVs create similar risks across institutions. Moreover, all campuses are subject to identical Federal Aviation Administration (FAA) regulations. For this study, four educational institutions' UAV policies from all fifty U.S. states were examined. The policies were classified from none to highly restrictive. Consistent with expectations, the stringency of UAV regulations is related to the institution's structure and mission. Publicly funded institutions, particularly the land-grant universities with relatively more community outreach, had the most restrictive policies. Institutions in states with local government ordinances restricting UAVs also tend to have stricter policies. More stringent UAV rules exist in research-oriented institutions. Neither organizational size nor the existence of an aviation program affects institutional UAV policies. Because some of the policies adopted in higher education go beyond the rules mandated by the FAA, some may label the elective policies as being excessive "red tape" that thwart the institutional mission and stymie research.
\end{abstract}

\section{INTRODUCTION}

\subsection{Overview}

When a controversial new technology emerges, diverse perspectives often compete to control its use. Much of the conflict typically centers around risk avoidance (Moreno, Todt, and Luján, 2010). At its outset, limited data are available to help guide policymakers regarding potential risks and benefits (Morgan, Henrion, and Small, 1992). Indecision prevails, and government policy, as well as private organizational responses to the innovation, can be steered by media "hype" and narrow organizational interests. The situation becomes even more complicated in a federalist political system. Short-term uncertainty rules the regulatory arena.

The number of Unmanned/Uncrewed Aerial Vehicles (UAVs) registered in the United States of America (U.S.) with the Federal Aviation Administration (FAA) now exceeds one million (U.S. Department of Transportation, 2018). The FAA predicts by 2022 that the number of small hobbyist UAVs to double and that the number of commercial UAVs to increase four-fold (Federal Aviation Administration, 2017). The initial media exposure covering the anticipated surge in UAV flights throughout the U.S. has reflected the public's concerns regarding personal invasions of privacy, along with strong apprehensions for potential bystander injury and property damage (Rule, 2016).

Academics and scientists are now embracing UAVs in their teaching and research, and institutions of higher education in the U.S. have taken a variety of approaches to self-regulate UAV flights by their employees and students. The diversity in institutional UAV policies provides appropriate data to study organizations' regulatory responses to a controversial innovation. All U.S. campuses reside beneath U.S. airspace, which is controlled by the federal government. Thus, all are subject to the identical Federal Aviation Administration (FAA) regulations controlling UAV use. Nationwide, higher education institutions share the joint mission of adult tertiary education, although the attention given to their ancillary missions of research and public service will vary. Moreover, all campuses are exposed to similar risks to health and property from UAV operations. Across higher education, these institutions differ in their attempts to self-regulate UAV operations. Self-imposed policies range from none to highly restrictive.

This study analyzes the organizational and environmental factors associated with the development of regulations controlling a controversial emerging technology. Colleges and universities, much like other organizations involved with technological innovations, are tasked with balancing their support for pioneering research and development against the possible risks to health and property.

\subsection{Federal UAV Policy}

Federal preemption is the foundation of U.S. aviation and its airspace; all regulatory airspace authority nationwide resides solely at the federal level. The FAA has been vested by the U.S. Congress with authority to regulate the national airspace. ${ }^{1}$

\footnotetext{
* Corresponding author

${ }^{1}$ See 49 U.S.C. $\$ 40103(\mathrm{a})(1) 1994$
} 
Furthermore, the FAA Modernization and Reform Act (FMRA) ${ }^{2}$ enacted by the U.S. Congress in 2012 authorized the FAA to ensure for the safe integration of pilotless aircraft (i.e., UAVs) into the national airspace. The FMRA classifies pilotless aircraft into one of three categories: 1) model, 2) public, and 3) civil. Within the FMRA, each of the three UAV categories has its own governing rules set. State, local, and private interests have no airspace authority except in restricting use by their employees or establishing rules regarding UAV flights from or on the premises.

Model aircraft constitutes a category that is the least regulated of the three FAA categories, as it had been exempted by prior federal law $^{3}$. Although operators of model aircraft must now register their aircraft with the FAA, they are exempted from the more stringent federal requirements imposed on civil and public UAV operators. Model aircraft are defined as those UAVs flown solely for recreational purposes without compensation, weigh no more than $25 \mathrm{~kg}$, and follow hobbyist community-based safety guidelines (Federal Aviation Administration, 2018b).

Public aircraft refer to those vehicles owned by federal, state, or local governments. These government-owned aircraft perform a wide-multitude of missions for their respective agencies. A controversial example is UAV use by local and state lawenforcement agencies for surveillance. Some local and state municipalities concerned with their citizens' privacy have selfrestricted their law-enforcement agencies in UAV operations (National Conference of State Legislatures, 2018).

Civil UAVs constitute the broadest category, encompassing all commercial "for-profit" applications and all operations not included under public and recreational flights of model aircraft. Most UAV flights for commercial applications were prohibited until 2016 when the FAA announced new rules designed to increase the number of commercial flights (Federal Aviation Administration, 2016). The regulations, commonly referred to as Part 107 of the FAA regulations, apply to all UAVs weighing 25 $\mathrm{kg}$ or less.

Under FAA guidelines (Federal Aviation Administration, 2018a), students and educational staff who fly UAVs fall into separate categories. The model aircraft exemption applies to students flying a UAV as part of academic coursework. These model aircraft guidelines apply to non-student UAV operators at educational institutions and community-sponsored events only if the person is neither compensated directly or incidentally related to the UAV operation. Since faculty and other staff who would use UAVs as part of their job duties usually receive compensation, they do not qualify for the model exemption and fall under the category of civil operators.

Flights by civil operators carry precise federal regulations. Registration of these UAVs with the FAA is required. Those operating or supervising a UAV flight must possess a remote pilot certificate with a small UAV rating. Airspace operational limits also apply. FAA rules stipulate permissible flight times and conditions that include altitude, speed, payload and cargo, and where the flight can occur. Pilots must ensure that the UAV is safe to fly and the vehicle must remain within the range of sight. Airspace operational limits also apply. Thus, all higher education staff interested in UAV flights are governed by federal governments regulations regardless of institutional policy.

\footnotetext{
${ }^{2}$ Bill Summary \& Status 112th Congress (2011 - 2012) H.R.658 CRS Summary P.L.112-95)
}

\subsection{Higher Education and Regulation of UAVs}

Higher education institutions have embraced both reluctantly and eagerly the evolving technology of UAVs. Administrators and faculty members view remotely piloted flight as offering new areas of study to their students as well as augmenting research in many disciplines (Gose, 2018). Faculty have promoted in their classes the advantages of UAVs for photography, mapping, safety, security, and other uses (Bendici, 2017). However, administrative concerns at some institutions have tempered its use. As extensively reported in the popular press, UAVs can potentially invade privacy and cause injury and property damage.

While some colleges and universities have responded to these risks by adopting stringent rules regarding UAV use for their employees, students, and visitors, other higher-education institutions have done nothing, or enacted few rules (e.g., some institutions only recite federal law). This analysis examines this variation.

\subsection{Innovation, the Precautionary Principle, and Red Tape}

Researchers point to the management of risk as a crucial element of technological innovation; risk is central to successful innovation (Rogers, 2003; Freeman and Soete, 1997). However, limited research exists on the role of risk in the adoption of emerging technologies (Brown and Osborne, 2013; Olson, Birge, and Linton, 2014).

Much of the debate regarding the management of risk with technological innovation centers on the application of the precautionary principle. This principle generally calls for actions to curtail risk where individuals can cite a plausible reason to suspect harm from a decision, but no scientific certainty prevails regarding the damage that might result. Interpretations of this principle vary widely, and no consensus exists on what the precautionary principle means for those who make decisions involving risk (Sunstein, 2005; Stewart, 2002).

Supporters of a strong version of the precautionary principle view regulation as essential even if the danger is purely speculative and the costs high (Sachs, 2011). They emphasize the importance of significant controls to minimize risk until a consensus determines that the level of risk is acceptable.

Critics of a strong interpretation of the precautionary principle argue that regulation based on unproven potential risks slows or even prevents technology advancement. Researchers view experimentation as crucial to the maximal development of the technology (Wiedemann and Schütz, 2005). However, risk management tends to discourage experimentation because of its focus on the control of uncertainty (Lee, Chung, and Kim, 2007). A decision to limit or even ban research because of a potential for adverse impacts could mean that the positive benefits from an innovation, which may be substantial, are unrealized.

Most commentators contend that FAA officials have exercised a strong interpretation of the precautionary principle in their development of regulations for the domestic UAV. Until 2016, all UAVs, including hobbyists' vehicles, had to be registered. Most commercial applications were prohibited. Those calling for less regulation during this period emphasized not only the economic benefit accruing from UAVs but also pointed to their contributions to "existing hazards," such as putting out fires

\footnotetext{
${ }^{3}$ FAA Reauthorization Act of 2018 Section 336
} 
(Jenkins and Vasigh, 2013). The media extensively covered the positive impact UAVs could have in multiple areas, especially agriculture. Proponents of looser regulations argued that the FAA policies, based on the potential for unproven potential harm, were resulting in substantial lost opportunities (Jenkins and Vasigh, 2013). Despite the regulatory changes that have produced a surge in pilotless flights in the U.S., FAA regulations remain conservative (National Academies of Sciences and Medicine, 2018).

Institutions that add regulations beyond those mandated by the FAA embrace a strong interpretation of the precautionary principle. Adopting rules to minimize risk provides definite advantages for organizational managers. Rules may protect from injury, increase organizational accountability, and add overall to a perception of care on the part of the organization (Katz and Kahn, 1966; Blau and Scott, 2003). Advocates of organizational restrictions beyond those imposed by the FAA can argue that although it has claimed preemptive authority, the FAA has not dealt adequately with the potential for property damage and injury at the local level, nor is it well-equipped to do so since local communities differ in their acceptance of UAV activity (Rule, 2016). UAVs have crashed into houses and outdoor gatherings. People complain of privacy invasions. Given the problems UAVs can create, additional measures to control them are necessary.

Skeptics of regulation maintain that the bureaucratic officials responsible for developing and overseeing regulations for a new technology often have little understanding of the technology they are tasked to control. A frequent response to uncertainty is to rely on procedural control mechanisms, such as mandating the submission of forms and training as a substitute for substantive control (Thompson, 1961).

When bureaucratic rules are viewed as unnecessary, or even impeding the organization's mission, complaints of "red tape" arise. Red tape consists of rules and procedures that negatively affect the organization's performance (Bozeman, 2000). Critics of strong UAV regulations argue that red tape resulting from additional regulations has plagued the integration of domestic UAVs into the U.S. (Hall and Coyne, 2014; Gordon, 2018; Rao, Gopi, and Maione, 2016). While they acknowledge potential problems that UAVs could produce, those critical of strong measure to minimize risk maintain that existing regulations would cover most or all of the potential problems. There are, for example, laws that protect against negligence (Clarke and Moses, 2014) and harassment, stalking and surveillance are illegal throughout the U.S. Protection from privacy invasion by a UAV are already provided by other areas of the law (Villasenor, 2013). Critics point out that Sweden backed away from including UAVs under its strict surveillance regulations because of a fear that the law would curtail commercial applications (McNabb, 2017).

The literature on organizational risk forms the basis for propositions regarding why U.S. colleges and universities have adopted different UAV policies. These propositions follow a description of the research procedure.

\section{DATA AND METHODS}

For each of the 50 states in the U.S. information was sought regarding the policy governing UAVs in the state's land-grant college, in its largest four-year public institution, and its two largest four-year not-for-profit private institutions by total student enrollment. Because Wyoming does not have a second public or non-profit private four-year institution the sample consists of 198 colleges and universities. Categorization of each of the 198 institutions took place using the Carnegie Classification of Higher Education, which classifies institutions as doctoral, masters, or baccalaureate-granting institutions (The Carnegie Foundation for the Advancement of Teaching, 2018). For these 198 institutions, 121 offer doctorates, 63 master's degree, and 14 baccalaureates. Institution size was measured using total student enrollment. Also, the UAV policy for the top 50 higher education institutions ranked by research and development expenditures was examined (Britt, 2016). Most of the top research universities overlap with the other three categories of education institutions.

Almost all of the higher education policies were available on their websites. Follow-up occurred with officials at the institution if a policy could not be found to determine if one existed. The most recent UAV plan was analyzed. Of the 198 colleges and universities in the sample, 86 had UAV policies. Two institutions would not provide their policy, giving 84 for analysis.

The authors performed the coding. Using the Holsti (1969) formula, the reliability score exceeded .80 for all categories. Coding for each institution's UAV policy included the following elements. First is whether institutional permission is required before a flight; second, the number of days before the scheduled flight that the operator must request approval; and third, the number of offices needed for approval of the flight. Other information regarding the UAV policy encompassed a dichotomous yes or no classification. These items included the following: a) Did the institution's policy describe FAA policy? b) Were FAA rules embedded or linked, and then considered part of the institution's policy? c) Did the institution state that operators of pilotless vehicles must comply with applicable laws? d) Was it mandatory to receive permission from the higher educational institution before purchasing a UAV? e) Before the flight, did the institution require any of the following: a description of the flight's purpose, the type of data sought, the flight plan, or the UAV's starting and ending flight times?

An additive scale score was constructed measuring the stringency of UAV regulations in each higher education institution. Each of the following in a policy added one point to the score: institutional permission required to fly a UAV, to purchase a UAV, and the permission sought more than two days before the scheduled flight. One point was added if the institution's policy requires permission from more than one office. Requiring a description of the flight's purpose, the data collection procedure, the flight plan, and the flight's starting and finishing time each added a point. The possible score ranges from zero to eight. Scores among the institutions ranged from zero to six. Collapsing the scores into three categories with zero to two measuring a low level of regulation, three and four a medium level, and five and six high produces the following distribution: 26 higher education institutions have policies with a high level of stringency, 21 a medium level of stringency and for 37 policies the level of stringency is low.

The number of words in each institutional UAV policy was determined using an online word counter. The count encompassed the institution's UAV policy and any forms that operators must complete and submit before a flight. The word count included FAA regulations described in policy unless they were embedded in separate links. The word count constitutes the measure of policy complexity. 
Institutions were categorized into three levels regarding size. Organizations classified as small have a total student enrollment of less than 20,000, medium-sized enroll between 20,000 to 35,000 students, and large institutions enroll over 35,000 students. Bard College's analysis of laws affecting UAVs enacted by local governments (Michel, 2017) provided the information regarding local government legislation restricting UAV use.

\subsection{Propositions}

The management literature that compares perceptions of red tape across different sectors leads to the expectation that public higher education institutions adopt more complex and more stringent UAV regulations than private higher education institutions. Although one study found that sector had little explanatory value in predicting the amount of red tape in an organization (Bozeman and Kingsley, 1998), other research finds that public sector employees perceive significantly more red tape than those in the private and nonprofit sectors (Feeney and Bozeman, 2009). Also supporting this proposition is research showing that public sector workers are more risk averse than private sector workers (Chen and Bozeman, 2012).

A second proposition is that public land-grant institutions adopt more complex and stringent UAV regulations than either nonland-grant institutions or private higher education institutions. Land-grant institutions differ from other types of educational institutions in that they receive a portion of their funding from the state, local, and federal governments. Their cooperative extension service increases their involvement in community outreach relative to their counterparts. Evidence suggests a positive relationship between outreach and state funding (Weerts and Ronca, 2006) and that organizations with higher levels of involvement with elected officials tend to possess a less risky culture (Bozeman and Kingsley, 1998). This proposition presumes that the fear of alienating both extension clients and government representatives will result in stricter UAV regulations.

Concern about antagonizing those outside of the higher education forms the basis for the prediction that institutions in states where local governments have passed legislation curtailing UAV flights have more stringent and complex UAV restrictions than institutions in states that have not had local governments adopt regulations restricting UAV flights. Local government action sends a message of apprehension about UAVs. Even if there is no direct interaction with the local officials, their political activity produces risk-averse responses.

Higher education institutions with doctoral programs are expected to have more stringent and complex UAV regulations than higher education institutions without doctoral programs. More complex organization possess less goal clarity and tend to exhibit less tolerance for risk than those with more specific goals (Thompson, 1967). While all colleges and universities embrace teaching, service, and research, the emphasis on research in doctoral institutions renders them more complex.

Also based on the literature on goal clarity is the prediction that higher education institutions with aviation programs have less complex and stringent UAV regulations than higher education institutions without aviation programs. The existence of an aviation program places a top priority on facilitating UAV flights. Thus, less stringent regulations will be in place.
The final expectation that larger institutions have more stringent UAV regulations than smaller institutions. Larger size produces greater structural differentiation that requires more managerial effort to coordinate the diverse groups. Research finds that larger organizations have higher levels of red tape (Pandey and Kingsley, 2000).

\section{RESULTS AND DISCUSSION}

Of the 198 institutions in the sample, 86 had UAV policies and 84 were publicly available. Most commonly found in the policies is a description of FAA regulations $(79 \%)$. Nearly half of the institution's UAV policies (46\%) state that those flying UAVs must abide by all local, state, and federal laws.

Figure 1 shows most $(85 \%)$ of the institutions with policies mandate that permission is granted in advance of a flight, and over half $(58 \%)$ require a description of the flight's purpose. While many of the policies do not specify how far in advance of the flight this permission be sought $36 \%$ require more than two days, and slightly over one-quarter of the policies $(27 \%)$ need a request for approval at least a week before the anticipated flight. Similarly, $34 \%$ of the higher education UAV policies stipulate that the pilots provide the starting and ending time of the flights and $37 \%$ mandate submission of a flight plan. In $30 \%$ of the policies, a description of the data collected during the flight is compulsory. Institutional permission to purchase a UAV is required in $17 \%$ of the policies.

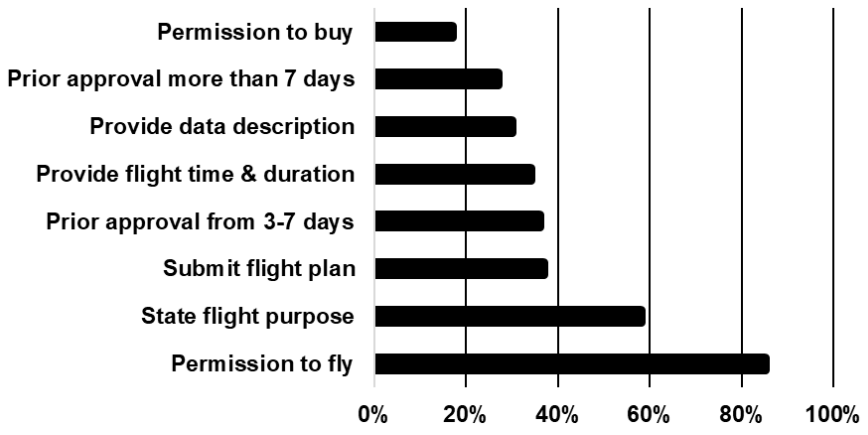

Figure 1. Institutions' additional self-imposed restrictions in UAV policies beyond FAA rules and regulations $(\mathrm{N}=198)$.

Table 1 displays the characteristics of higher education institutions with UAV policies. If the adoption of a policy shows concern over UAV flights, interest appears limited to certain types of institutions. Land-grant institutions are most likely to adopt a policy with $92 \%$ compared to $49 \%$ of the non-land-grant public institutions and $18 \%$ of the private institutions. Also consistent with expectations, with few exceptions only institutions with doctoral programs adopt UAV policies. Of the 198 higher education institutions analyzed, $69 \%$ of the doctoral institutions contain a UAV policy, while only three of the master's programs and one of the baccalaureate institutions have a policy regarding uncrewed flight (Table 2).

\begin{tabular}{|l|c|}
\hline Institutional Type & Have UAV Policy \\
\hline Land-Grant University & $92 \%$ \\
Largest Public University & $49 \%$ \\
Two Largest Private Universities & $18 \%$ \\
\hline
\end{tabular}

Table 1. Type of institutions with UAV policies $(\mathrm{N}=198)$. 


\begin{tabular}{|l|c|c|}
\hline Highest Degree & $\mathrm{N}$ & Have policy \\
\hline Doctoral & 121 & $69 \%$ \\
Masters & 63 & $5 \%$ \\
Baccalaureate & 14 & $7 \%$ \\
\hline
\end{tabular}

Table 2. Institution highest degrees granted and percent having a UAV policy $(\mathrm{N}=198)$.

Policy complexity, as measured by word count, varies. The smallest UAV policy consists of 28 words and the longest 5,690 words. Public institutions, particularly land-grant colleges, have the most complex policies. Dividing up the institutions by landgrant status, non-land-grant public schools, and private schools show that the most complex policies are found in land-grant institutions with a mean of 1,713 words per policy followed by public non-land-grant with a mean word count of 1,514 . Lowest in complexity are the policies of private schools, with a mean word count of 1,361 . The ordering is as expected with the most complex policies adopted by the land-grant schools and the least complex enacted by private institutions. However, the twosample t-tests conducted shows that the differences in word count among the three types of institutions lack statistical significance.

Other elements of the analysis support the findings of other researchers who conclude that public sector organizations tend to place more emphasis on controlling employees and following a mandated process. Besides the fact that public institutions are much more likely to adopt a policy, the policies adopted by public institutions are more stringent than those adopted by private schools. Comparisons of stringency are limited because of the eighteen private colleges with policies in this sample; two were not made available. Of the sixteen policies examined, $31 \%$ of 99 are categorized as high stringency and $50 \%$ as low with $19 \%$ in the middle. The public institutions have adopted more stringent policies. Of the 70 public institution policies, $37 \%$ have a high level of stringency, $27 \%$ are categorized as medium stringency, and $36 \%$ are low stringency. The policy scale scores were collapsed from three levels into two to allow a statistical test. Scale scores of policy stringency of zero, one, and two were combined with the states with no UAV policy to form a category of low stringency. Scores of three and above were considered high stringency. All statistical tests using Fisher's exact test in this analysis collapsed the data in this manner. The difference in the stringency scores between the public and private higher education institutions is statistically significant $(\mathrm{p}<.001$, Fisher's exact test).

All the land-grant colleges reviewed offer doctoral programs. To determine whether the land-grant status is associated with more stringent policies independent of their doctoral status the stringency of land-grant UAV policies was compared with the non-land-grant doctoral institutions' policies. The doctoral institutions were collapsed into two categories: lower and higher stringency. Institutions without a policy were included in the low category. Over half of the land-grant schools (54\%) have a policy coded as higher in restrictiveness compared to $10 \%$ of the other (private and public non-land grant) doctoral institutions. The difference is statistically significant $(\mathrm{p}<.001$, Fisher's exact test). Although the difference in word count is not statistically significant, land grant institutions adopt more complex policies than non-land grant doctoral institutions. The mean number of words in the land grant schools is 1,713 words compared to 1,428 words in the non-land grant doctoral institutions.

Considerable variation exists in higher education's UAV policies. Table 4 compares the UAV regulations adopted by the 50 top research universities with other categories of higher education institutions. Table 4 shows that land grant public institutions have the most stringent regulations followed by the top 50 research institutions. Among the public land-grant schools almost two-thirds have a policy categorized as high or medium stringency $(66 \%)$ compared to nearly half of the top 50 research institutions $(47 \%)$. Falling considerably below in stringency are the public non-land grant institutions and the private colleges and universities. Over half of the largest public, non-land grant institutions have no policy regarding UAVs (51\%), and almost a third have a policy low in stringency $(31 \%)$. Private institutions show even less concern with $82 \%$ without a policy and only $8 \%$ with policies categorized as medium or high stringency.

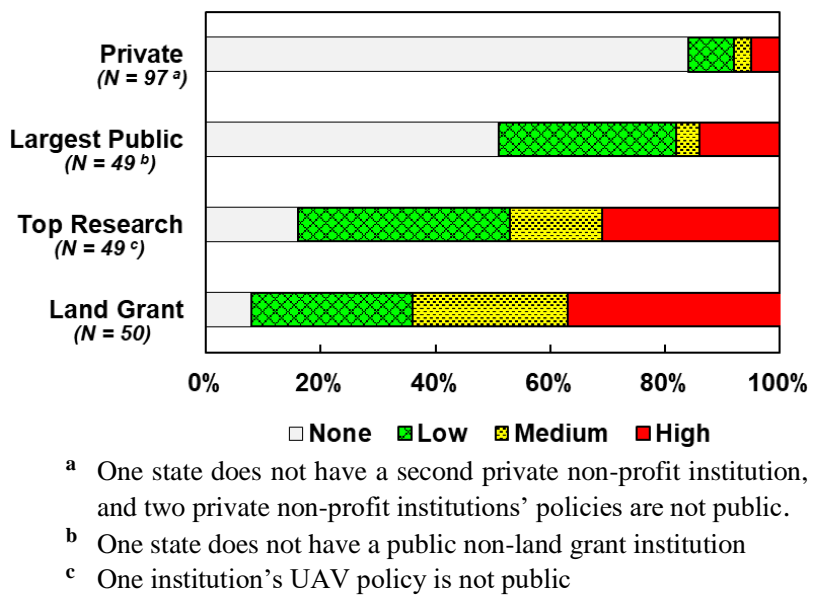

Figure 2. Institution's stringency level of UAV policy.

Contrary to expectations, organizational size does not appear related to the stringency of the regulations nor the complexity of the policies. Policies of high stringency are found in $45 \%$ of the large organizations compared to $28 \%$ of the medium-sized organizations and $33 \%$ of the small. The percentage of institutions with policies of low stringency was similar for the three categories of institutions based on size. Differences in the stringency of policies are not statistically significant (Fisher's exact test) nor are the differences in complexity as measured by word count.

Also contrary to expectations is that no firm evidence exists to link aviation programs with more lenient UAV regulations or policies lower in complexity. Aviation programs are concentrated in land-grant colleges; 21 of the 50 land-grant schools have an aviation program. Only 19 of the private and non-land-grant public institutions in this sample offer aviation. Of these institutions, 11 have a policy and eight do not. No statistically significant differences were found in the complexity of the policies as measured by word count. The stringency of the policies in institutions with an aviation program was compared with the stringency of the policies of institutions without an aviation program policy. The differences in policy stringency are not statistically significant (Fisher's exact test).

States with local legislation regulating UAV flights are more likely to have at least one institution of higher learning with highly restrictive UAV regulations than states where local governments have not enacted UAV ordinances. Of the 50 states, 31 have one or more laws adopted by local governments to regulate UAV flights (Michel, 2017). From each state, the institution in this data set with the strictest scrutiny was used for comparison. Of the 31 states with local level restrictions, 53\% have an institution with a categorization of high scrutiny in this data set compared to $21 \%$ of states without local legislation. 
While $58 \%$ of the states with no local UAV laws have all institutions in this sample categorized as low in UAV restrictions (i.e., no policy or the policy is of low stringency), this is the case for only $27 \%$ of the states with local legislation. States that have one or more local governments that have adopted ordinances restricting UAVs are more likely to have higher education institutions with a UAV policy of high stringency than states that have not had local governments adopt restrictive UAV ordinances. The difference is statistically significant (Fisher's exact test, $\mathrm{p}=.04$ )

More stringent UAV restrictions characterize land-grant colleges, public institutions, especially those offering a doctoral degree, and institutions in states where local governments have adopted UAV restrictions. Organizational size does not matter nor does the existence of an aviation program at the institution. These findings suggest the importance of public relations concerns on organizational rules. Land-grant colleges, which have relatively high interaction with political officials and members of the community, have enacted the most stringent and complex regulations. Institutions have stricter regulations when one or more local governments adopt UAV restrictions. The institution may be responding to political pressure from the local government or the discussion generated by the municipal action created a consensus that the educational institution should also act.

UAV policy does not appear to be driven by the amount of interest in pilotless flight or institution size. Although doctoral institutions adopt more stringent policies, institutions with aviation programs do not enact stronger regulations than those without these programs. Also, student enrollment is not associated with the type of UAV policy adopted.

The UAV policies adopted by higher education institutions appear in large part to be directed toward researchers. Over onehalf of the institutions in this analysis have no policy although all institutions surely enroll some students interested in uncrewed flight. Further, many of the institutions without a policy are situated in urban areas close to airports where flights could prove particularly hazardous. The specific information sought before permission is granted to fly in many institutions appears to be geared toward controlling research-oriented UAV flights.

This analysis cannot determine the effectiveness and efficiency of each UAV policy. Responses to request to fly may be rapid with permission granted to all reasonable requests. Rules may be ignored without penalty. However, it does seem that some researchers will find certain elements burdensome. Particularly problematic is the requirement that permission must be sought days or even weeks in advance of a flight and that the flights adhere to the time frame specified. Given the uncertainty that weather conditions and travel requirements create for UAV flights and the possibility of something needing repair mandating notice weeks in advance creates a hardship. Because numerous factors can disrupt a flight restricting permission to a particular time range will result in missed opportunities for data collection.

Institutions that require a detailed description of the data collected and a flight plan are understandably trying to avoid complaints regarding a nuisance, trespass, or privacy violations. However, other research contexts that create the potential of damage do not carry a detailed description of research plans. For example, automobiles involve the potential to inflict significant damage, but educational institutions usually allow employees access to a vehicle after doing nothing more than showing a stateissued license. Many of these policies mandate far more than proving that the individual is authorized by the FAA to fly a UAV.

Red tape is a matter of opinion. Some view a university's detailed listing of FAA requirements as redundant and the warning that one must obey the law as obvious and unnecessary. One can also question whether restrictions that exceed the regulations allowed state and local governments constitute red tape given the research mission of many institutions. Many higher education UAV policies require that all flights occur within the line of sight. This restriction was struck down in a local ordinance because it created limits on navigable airspace, and thus violated FAA authority (Michel, 2017). An individual can receive a waiver from the FAA of Part 107 regulations. Waivers are not available in most of these institutional policies. Thus, many institutions have policies and stipulate punishments, including dismissal from employment, for violations of rules that the FAA defines as permissible or potentially permissible.

Many researchers face a regulatory burden. They must comply with external requirements imposed by law, explicit regulation, or guidance provided by regulatory agencies. They must also follow the internal mandates not required by law or regulation but by institutional self-imposed standards and processes (Haywood and Greene, 2008). Regulatory requirements on research in the U.S. are expanding, and investigators report that the administrative activities required for compliance significantly detracts from research (Schneider et al., 2014; Thulin, Bergdall, and Bradfield, 2018; National Academies of Sciences and Medicine, 2016).

While university administrators can do little or nothing to reduce the administrative burden created by mandatory standards, they do determine their institution's elective requirements. Research shows considerable variation across campuses in self-imposed requirements relating to human subject institutional review boards (Abbott and Grady, 2011) and in the care of animals in research (Haywood and Greene, 2008).

UAVs create risk. Institutions will maximize research efforts by creating rules that result from a process and culture geared toward facilitating research while also protecting the institution from the consequences of noncompliance with laws and regulations (Bayne and Garnett, 2008). This type of culture is achieved when stakeholders are engaged in the development of internal regulations, the purpose of internal regulations is clear, and there are no unnecessary processes.

Institutional rules for a controversial technology are often dynamic. UAVs, like many emerging technologies, have been subjected to "hype". Their potential problems as well as their potential contributions have been exaggerated (Freeman and Freeland, 2016). When more data regarding risks become available, there is likely to be greater uniformity in rules. Studies suggest the periodic assessment of internal regulations with the goal of identifying any parts of the process not needed or too inflexible (Haywood and Greene, 2008; Bayne and Garnett, 2008; Thulin, Bergdall, and Bradfield, 2018).

The shortcomings of the analysis should be noted. A larger number of cases would allow more sophisticated data analysis. The sample was not expanded because no systematic approach to substantially increase the number of institutions with UAV policies was evident since UAV policies are concentrated in public, doctoral-granting institutions. 


\section{SUMMARY AND CONCLUSIONS}

Decisions regarding the amount of risk acceptable with an emerging technology involve a trade-off between advances in research and development and the political controversy and damage possible from deploying the technology. This study examines this dynamic through an analysis of the regulations of UAVs adopted in U.S. higher educational institutions. The literature on organizational risk and institutional "red tape" informed the propositions regarding the type of colleges and universities in the U.S. most likely to adopt complex, restrictive regulations. The data for the analysis consists of higher education institutions' UAV policy. UAV policies were sought from 200 institutions: the public land-grant institutions, the largest public institution and the largest and second-largest nonprofit private institution in student enrollment in each of the 50 states.

Consistent with expectations, doctoral institutions adopted more regulations than those without doctoral programs. Also consistent with expectations is the finding that public institutions adopt more regulations than private and that land-grant colleges particularly adopted self-restrictive UAV regulations. States with local governments that have enacted UAV restrictions are more likely to have a higher education institution with stricter regulations regarding UAVs. The findings suggest that concern for external public relations and publicity drives regulation. Neither the existence of an aviation program nor institution size is related to the institution's UAV policy. Policy complexity, measured by the number of words in the UAV policy varied among the institutions in the expected direction. However, the differences were not statistically significant.

Red tape exists when the impact of regulations proves detrimental to the institution's mission. While some of the policies do nothing more than detailing FAA guidelines, other policies mandate procedures that make it far more challenging to conduct UAV research. Some researchers at these institutions no doubt chafe at operating under more stringent regulations than other institutions, arguing that the risk presented by UAVs does not justify the "red tape."

Although considerable research takes place in doctoral institutions, few studies have examined the degree to which higher education institutions differ in their acceptance of risk. These findings suggest the importance of analyzing regulations regarding risk for other emerging technologies to determine the degree to which these findings regarding institutional variance in regulations can be generalized.

\section{ACKNOWLEDGEMENTS}

The United States Department of Agriculture (USDA) National Institute of Food and Agriculture, Hatch Project TN00459, and Multistate Research Project S1069 supported this work.

\section{REFERENCES}

Abbott, Lura, and Christine Grady. 2011. "A systematic review of the empirical literature evaluating IRBs: what we know and what we still need to learn." $J$ Empir Res Hum Res 6 (1):3-19. doi: doi.org/10.1525/jer.2011.6.1.3.

Bayne, Kathryn A, and Nelson L Garnett. 2008. "Mitigating risk, facilitating research." ILAR J 49 (4):369-71. doi: doi.org/10.1093/ilar.49.4.369.
Bendici, Ray. 2018. "The drone zone in higher education." University Business, Accessed 20 August 2018. universitybusiness.com/article/drone-zone-highereducation.

Blau, Peter Michael, and W Richard Scott. 2003. Formal organizations: A comparative approach: Stanford University Press.

Bozeman, Barry. 2000. Bureaucracy and red tape: Prentice Hall. Bozeman, Barry, and Gordon Kingsley. 1998. "Risk culture in public and private organizations." Public Admin Rev 58 (2):109-18. doi: doi.org/10.2307/976358.

Britt, Ronda. "Universities report fourth straight year of declining federal R\&D funding in FY 2015." Accessed $14 \quad$ January 2019 nsf.gov/statistics/2017/nsf17303/nsf17303.pdf.

Brown, Louise, and Stephen P Osborne. 2013. "Risk and innovation: Towards a framework for risk governance in public services." Public Manag Rev 15 (2):186-208. doi: doi.org/10.1080/14719037.2012.707681.

Chen, Chung-An, and Barry Bozeman. 2012. "Organizational risk aversion: comparing the public and non-profit sectors." Public Manag Rev 14 (3):377-402. doi: doi.org/10.1080/14719037.2011.637406.

Clarke, Roger, and Lyria Bennett Moses. 2014. "The regulation of civilian drones' impacts on public safety." Comput Law Secur Rev 30 (3):263-85. doi: doi.org/10.1016/j.clsr.2014.03.007.

Federal Aviation Administration. "Advisory Circular 107-2 (Small Unmanned Aircraft Systems)." Accessed 14 January 2019. faa.gov/uas/resources/policy_library/media/ac_1072_afs-1_signed.pdf.

"Fact Sheet - Federal Aviation Administration (FAA) Forecast Fiscal Years (FY) 2017-2038. ." Accessed 28 August 2018. faa.gov/news/fact_sheets/news_story.cfm?newsId=22 594.

2018. "Educational Users." Accessed 9 June 2018. faa.gov/uas/educational_users/.

2018. "Recreational Fliers \& Modeler CommunityBased Organizations." Accessed 9 June 2018. faa.gov/uas/recreational_fliers/.

Feeney, Mary K, and Barry Bozeman. 2009. "Stakeholder red tape: Comparing perceptions of public managers and their private consultants." Public Admin Rev 69 (4):710-26. doi: doi.org/10.1111/j.15406210.2009.02019.x

Freeman, Chris, and Luc Soete. 1997. "The economics of industrial revolution." Pinter, London.

Freeman, Patricia K, and Robert S Freeland. 2016. "Media framing the reception of unmanned aerial vehicles in the United States of America." Technol Soc 44:23-9. doi: doi.org/10.1016/j.techsoc.2015.11.006.

Gordon, Sarah. "Drones take flight for businesses that can navigate red tape." Accessed 21 August 2018. ft.com/content/2107f088-f53e-11e7-8715e94187b3017e.

Gose, Ben. "Did you know you could major in drones? ." Accessed 21 August 2018. chronicle.com/article/DidYou-Know-You-Can-Major-in/243019.

Hall, Abigail R, and Christopher J Coyne. 2014. "The political economy of drones." Defence Peace Econ 25 (5):44560. doi: doi.org/10.1080/10242694.2013.833369.

Haywood, JR, and Molly Greene. 2008. "Avoiding an overzealous approach: a perspective on regulatory burden." ILAR J 49 (4):426-34. doi: doi.org/10.1093/ilar.49.4.426. 
Holsti, Ole R. 1969. Content Analysis for the Social Sciences and Humanities. Reading. MA: Addison-Wesley.

Jenkins, Darryl, and Bijan Vasigh. 2013. The economic impact of unmanned aircraft systems integration in the United States: Association for Unmanned Vehicle Systems International (AUVSI).

Katz, Daniel, and Robert L Kahn. 1966. The social psychology of organizations: Oxford, England: Wiley. .

Lee, Youngseok, Dongjin Chung, and Youngjin Kim. 2007. "Public R\&D Risk and Risk Management Policy." Int J Soc, Behav, Educ, Econ, Bus, Indust Engr 1 (10):508-11.

McNabb, Miriam. "Are Drone Regulations Protecting Your Privacy?" DRONELIFE, Accessed 21 August 2018. dronelife.com/2017/04/11/drone-regulationsprotecting-privacy/.

Michel, A Holland. 2017. "Local and State Drone Laws." Center for the Study of the Drone, Bard College.

Moreno, Carolina, Oliver Todt, and José Luis Luján. 2010. "The context (s) of precaution: Ideological and instrumental appeals to the precautionary principle." Sci Commum 32

(1):76-92

doi: doi.org/10.1177/1075547009340342

Morgan, Millett Granger, Max Henrion, and Mitchell Small. 1992. Uncertainty: a guide to dealing with uncertainty in quantitative risk and policy analysis: Cambridge university press.

National Academies of Sciences, Engineering, and Medicine. 2016. Optimizing the Nation's Investment in Academic Research: A New Regulatory Framework for the 21st Century. Washington, DC: The National Academies Press.

2018. Assessing the Risks of Integrating Unmanned Aircraft Systems (UAS) into the National Airspace System. Washington, DC: The National Academies Press.

National Conference of State Legislatures. "Current Unmanned Aircraft State Law Landscape." Accessed 9 January $2019 . \quad$ ncsl.org/research/transportation/currentunmanned-aircraft-state-law-landscape.aspx.

Olson, David L, John R Birge, and Jonathan Linton. 2014. "Introduction to risk and uncertainty management in technological innovation." Technovation 34 (8):3958. doi: doi.org/10.1016/j.technovation.2014.05.005.

Pandey, Sanjay K, and Gorden A Kingsley. 2000. "Examining red tape in public and private organizations: Alternative explanations from a social psychological model." J Publ Adm Res Theor 10 (4):779-800.

Rao, Bharat, Ashwin Goutham Gopi, and Romana Maione. 2016. "The societal impact of commercial drones." Technol Soc 45:83-90. doi: doi.org/10.1016/j.techsoc.2016.02.009.

Rogers, Everett M. 2003. The Diffusion of Innovation 5th ed: New York: Free Press.

Rule, Troy A. 2016. "Drone zoning." N C Law Rev 95 (1):133.

Sachs, Noah M. 2011. "Rescuing the strong precautionary principle from its critics." U Ill Law Rev: 1285.

Schneider, SL, KK Ness, S Rockwell, K Shaver, and R Brutkiewicz. "Federal Demonstration Partnership (FDP) 2012 Faculty Workload Survey Research Report." April, Accessed 14 January 2019. sites.nationalacademies.org/cs/groups/pgasite/docum ents/webpage/pga_087667.pdf.

Stewart, Richard B. 2002. "Environmental regulatory decision making under uncertainty." In An introduction to the law and economics of environmental policy: Issues in institutional design, 71-126. Emerald Group Publishing Limited.

Sunstein, Cass R. 2005. Laws of fear: Beyond the precautionary principle. Vol. 6: Cambridge University Press.

The Carnegie Foundation for the Advancement of Teaching. "A classification of institutions of higher education." $\begin{array}{llll}\text { Accessed } & 21 & \text { August }\end{array}$ carnegieclassifications.iu.edu/.

Thompson, James D. 1967. Organizations in action: Social science bases of administration: New York: McGrawHill.

Thompson, Victor A. 1961. Modern Organization: A General Theory. New York, NY: Alfred A. Knopf.

Thulin, JD, VK Bergdall, and JF Bradfield. 2018. "Facilitating the Research Process: Limiting Regulatory Burden and Leveraging Performance Standards.". In: Weichbrod RH, Thompson GAH, Norton JN, editors. Management of Animal Care and Use Programs in Research, Education, and Testing. 2nd edition. Boca Raton (FL): CRC Press/Taylor \& Francis; 2018. Chapter 10.

U.S. Department of Transportation. "FAA Drone Registry Tops One Million.", Accessed 14 January 2019. transportation.gov/briefing-room/faa-drone-registrytops-one-million.

Villasenor, John. 2013. "Observations from above: unmanned aircraft systems and privacy." Harv J Law Publ P $36: 457$.

Weerts, David J, and Justin M Ronca. 2006. "Examining differences in state support for higher education: A comparative study of state appropriations for research I universities." J High Educ 77 (6):935-67. doi: doi.org/10.1353/jhe.2006.0054.

Wiedemann, Peter M, and Holger Schütz. 2005. "The precautionary principle and risk perception: Experimental studies in the EMF area." Environ Health Persp 113 (4):402. doi: doi.org/10.1289/ehp.7538. 